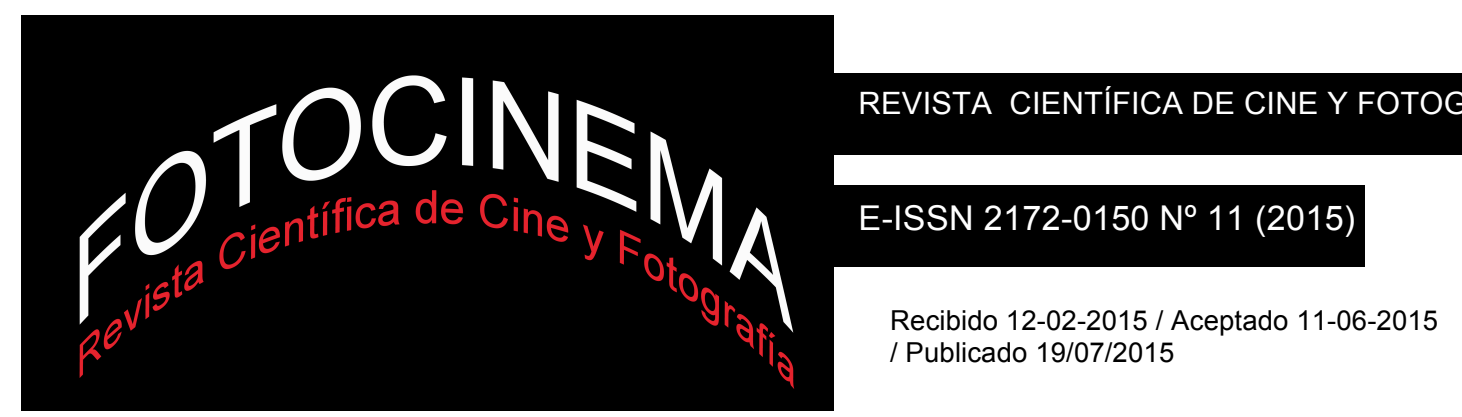

\title{
FOTOPERIODISMO CON EL MÓVIL: ¿EL FIN O REINVENCIÓN DE LOS FOTÓGRAFOS DE PRENSA?
}

\section{MOBILE PHONE PHOTOJOURNALISM: THE END OR THE REINVENTION OF PRESS PHOTOJOURNALIST?}

\author{
Eva Lavín de las Heras \\ Universidad Camilo José Cela, España \\ elavin@ucjc.edu \\ Dr. Max Römer Pieretti \\ Universidad Camilo José Cela, España \\ mwalter@ucjc.edu
}

\section{Resumen:}

Internet, las redes sociales y la evolución tecnológica han provocado un cambio en el paradigma informativo, afectando en una mayor proporción al fotoperiodismo de prensa. El aumento en la resolución de las cámaras de los móviles, ha permitido que un aficionado pueda hacer una foto publicable, que además a través de Internet $\mathrm{y}$ las redes sociales, se propague rápidamente entre millones de usuarios. $Y$ por ende, que las agencias y los medios de comunicación las utilicen cuando se produce un suceso importante. Estos han descubierto una nueva fuente de información que les proporciona material gratuito. Además, algunos medios ya han despedido a sus fotógrafos y los han reemplazado por smartphones. Pero por el contrario, hay otros fotógrafos e investigadores que ven con mayor optimismo los nuevos medios que se le presentan, afirmando que se abre ante ellos una nueva época dorada. En este artículo investigaremos cuál es el estado del fotoperiodismo, des el fin o la reinvención de los fotógrafos de prensa?.

\begin{abstract}
:
The Internet, social networks and technological developments have caused a change in the news paradigm, affecting an ever-increasing proportion of the photojournalism process. The increase in the resolution of camera phone photographs has enabled an amateur to take publishable photos, then rapidly spread it among million of users through internet-based social networks. Many news agencies and media outlets now rely on these freelyavailable amateur photographs as a reliable source of up-to-the-minute photographic information. Also, some news companies have even dismissed their photographers entirely and replace them by smartphones. Despite this, some photographers and researchers are optimistic about the new tools and believe they may usher in a new golden age in photojournalism. In this article, we investigate the current state and future of photojournalism, and ponder if this marks the end or simply a reinvention of the role of press photographers.
\end{abstract}

\section{Palabras clave:}

fotoperiodistas; Instagram; fotografía; redes sociales; smartphones

\section{Keywords:}

Photojournalist; Instagram; Photography; Social Networks; Smartphones 


\section{Introducción}

La fotografía según el fotógrafo Pablo Corral (2012) nace ligada a la tecnología porque de todos los lenguajes es el que más necesita una plataforma técnica para existir.

La historia de la fotografía se podría dividir en tres fases según Campany (2007). En la primera, la fotografía fue durante décadas un medio lento y voluminoso, tanto en el proceso técnico como en la implantación social, sólo a partir de 1920, con el dominio del periodismo impreso y el avance tecnológico se convirtió en el medio definitivo y modulador del acontecimiento. En esta segunda fase, se consideraba que los buenos fotoperiodistas eran los que iban detrás de la acción. Pero duró hasta principios de los setenta, cuando se produjo la introducción masiva de las cámaras de televisión que acaparó la definición de un acontecimiento y que en los últimos años se ha repartido entre la variedad de tecnologías mediáticas.

En la actualidad gracias a Internet, las redes sociales y/o el bajo precio de los teléfonos inteligentes equipados con cámaras fotográficas de calidad, los fotógrafos profesionales han perdido la exclusividad del lenguaje fotográfico. Ahora millones de personas pueden tomar instantáneas y compartirlas a su vez con millones de personas prácticamente en cuestión de segundos, algo que está perjudicando su trabajo.

La primera democratización de la fotografía, se produjo a principios del siglo XX, con la fabricación industrial de la película fotográfica, que permitió la creación de la primera cámara de cine y las primeras cámaras de cajón de los aficionados, lo que dio acceso a millones de personas, cuando antes estaba limitado sólo a los profesionales (Corral, 2012). En los años 30 gracias a la creación de nuevas técnicas de impresión, como la del color, así como la transmisión de las fotografías por belino, los fotoperiodistas vivieron un gran momento. Aparecen las revistas fotográficas en Alemania con un nuevo estilo, en el que predominaba la imagen sobre el texto, las series de fotografías eran las encargadas de contar las historias. Este estilo tuvo una 
gran influencia, más tarde, en la revista $V u$ en Francia y las americanas Life o Look (Freund, 2011).

Pero la aparición de la televisión, hizo que las revistas semanales no pudieran competir en inmediatez, y según Campbell (2010) desde que cerraron sus puertas, Look en 1971 y Life en 1972, la muerte del fotoperiodismo se mueve a intervalos regulares.

Otro punto de inflexión se produjo durante la primera guerra del Golfo, en 1991, en el que sólo se acreditó a 33 fotógrafos y los centros de revelado que se les construyó, estaban situados a unas tres horas de la zona de combate, de tal forma, los militares podían controlar y evitar las imágenes de solados aliados muertos o heridos y de las víctimas iraquíes (Suárez, 2013). La televisión monopolizó el reino de la imagen, emitiendo los vídeos de los ataques proporcionados por el Departamento de Defensa norteamericano, que prácticamente fueron las únicas imágenes del conflicto. La prensa y las revistas, no se quedaron atrás y extrayendo fotogramas de estos vídeos ilustraron sus portadas. Autores como Pizarroso et al. (2007) consideran que supuso el principio del fin del fotoperiodismo, otros como Braojos et al. (1999), un cambio de paradigma del periodismo.

Pero es en la actualidad, la época en la que estamos viendo las consecuencias más evidentes de esta democratización con la aparición del llamado periodista ciudadano. Los medios de comunicación utilizan imágenes obtenidas de las redes sociales, fotoperiodistas son despedidos y el trabajo de los freelance se está depreciando, por ello, consideramos fundamental estudiar el estado del fotoperiodismo en la actualidad, tras los nuevos avances tecnológicos y el nuevo paradigma comunicativo.

Este trabajo pretende ser descriptivo de una situación que, por tratarse de un fenómeno reciente en el mundo del periodismo, está siendo reflexionado, contabilizado y, sobre todo vivido en los medios de comunicación y leído por los ciudadanos que a la vez se hacen protagonistas de la información fotográfica. 


\section{Marco teórico y metodología}

Hay diversas opiniones sobre cómo está afectando las nuevas evoluciones tecnológicas a la fotografía. Algunos como Lister (2011) consideran que los problemas que existen se ven agravados por éstas en lugar de ser resueltos por ellas, y que se puede hablar de una edad oscura digital. Campany (2007) ve prematuros los mensajes sobre "la muerte del fotoperiodismo", considera que la redefinición de las posibilidades está empezando a emerger buscando nuevos contextos y aludiendo a diferentes enfoques. En esta línea también está Corral (2012), que considera que en un mundo en el que casi todos pueden expresarse fotográficamente, habrá muy pocos que puedan vivir de la fotografía, pero cree que el lenguaje fotográfico se ve revitalizado por la participación de millones de nuevos practicantes y que abrirá caminos renovadores con nuevos discursos y estéticas.

Marinello es mucho más positivo y afirma que la aparición de Internet "ha constituido una sorprendente y renovada plataforma medial” (1996, p. 68) en la que la fotografía aparece rejuvenecida y encuentra un sólido lugar en las páginas web dónde su lectura "original y única que ha permanecido y permanecerá en la era digital” (1996, p. 70). Investigadores como Irala (2011) ven Internet como un medio útil y atractivo para la divulgación pública de sus trabajos, permitiendo así a los fotógrafos multiplicar las posibilidades de difusión. Campbell (2010) además de confirmarlo, asegura que al eliminar los costes de publicación y por tanto, las barreras, permite ampliar los límites que tenía la comunicación tradicional, permitiendo que la audiencia de sus historias crezca. Afirma que en este contexto, es cuando habla de la muerte del fotoperiodismo, sobre el fin de los sistemas de distribución tradicional (prensa, libros, exhibiciones, etc.) más que como el final de una forma visual de información.

Pero es una realidad, que las nuevas tecnologías han permitido que, en la actualidad, cualquiera pueda hacer una fotografía y la comparta con millones de usuarios. Los medios de comunicación no se han mantenido al margen y están aprovechando este fenómeno en su propio beneficio, cuando un suceso acontece, acuden a las redes sociales para obtener material 'gratuito' con 
gran inmediatez. Rebajando el nivel de calidad, emitiendo imágenes y fotografías que años atrás se hubieran descartado.

Desde el punto de vista teórico, se puede concluir que dos teorías sobre el futuro de la profesión son antagónicas, oscilando entre su muerte definitiva y la apertura de nuevos e insospechados horizontes, razón por la cual en este artículo se describen algunos factores para llegar a una aproximación a la pregunta: ¿̇es el fin o la reinvención del fotoperiodismo?

Internet acabó con el monopolio de la información, cualquiera a través de las redes sociales puede colgar una fotografía de un acontecimiento que se acaba de producir y no sólo llegar a millones de personas sino que además salga en la portada de los principales periódicos mundiales como ocurrió en los atentados terroristas de Londres del 7 de julio de 2005.

El periodismo ciudadano y el cambio del nuevo paradigma informativo ha sido estudiado por numerosos investigadores, como Salvat y Paniagua (2007), Maciá Barber (2007), Real, Agudiez y Príncipe (2007) o Tognazzi (2012), dando lugar a miles de estudios, pero el fotoperiodismo ciudadano también está afectando al sector y por el contrario ha sido menos estudiado. Autores como Bernardo Riego afirman que la fotografía "como medio tecnológico no está muerto, sino en una nueva encrucijada” (2015, p. 17) en el que los límites se vuelven difusos. Pero ¿́podemos considerar periodista al ciudadano que hace una fotografía que luego utilizan los medios de comunicación? ¿Qué efecto tiene sobre el fotoperiodismo este nuevo participante de la información? ¿Pueden competir los fotoperiodistas con los millones de personas que tienen un móvil con cámara de fotos y acceso a Internet?

Es evidente que un fotógrafo pocas veces se encontrará en el lugar del suceso cuando algo acontece, pero en coberturas programadas, ¿qué pasa? En consecuencia, la pregunta de investigación que mueve a esta investigación es ¿un redactor con un iphone puede suplir al fotoperiodismo profesional? 


\section{Exposición}

\subsection{Fotografía digital e Internet}

El fotógrafo cuenta con una serie de herramientas para construir su mensaje, reforzar, matizar o desmentir datos, como afirma Irala (2011a) y la fotografía digital les ha facilitado el trabajo gracias a los avances.

La fotografía digital ha permitido que se elimine el proceso de revelado, trabajo que muchas veces hacía peligrar el trabajo de estos profesionales. Robert Capa tras inmortalizar el desembarco de Normandía en la playa Omaha, envió sus carretes a la redacción de la revista Life pero las prisas hicieron que en el laboratorio cerraran las puertas en el armario donde se secaban los negativos y el calor, los derritió. De los cuatro carretes con 106 fotografías solo se pudieron salvar 11 (Kuper, 2013).

Miguel Gil, fotógrafo español, se encontró un problema parecido cubriendo la guerra de los Balcanes. Los compañeros de la agencia Reuters, dónde Miguel iba a revelar sus fotos, confundieron el revelador con el fijador y arruinaron los dos carretes con imágenes de refugiados y de un bombardeo en Mostar, algo por lo que se había jugado la vida (Martí, 2001).

Otras de las limitaciones que tenía la fotografía analógica y que desaparece con la digital, es la limitación de fotos que permitía el carrete, actualmente las tarjetas de memoria que emplean las cámaras pueden almacenar miles de imágenes. Una de las fotografías que recorrió todo el mundo, fue la realizada por el fotógrafo de la agencia AP, Huynh Cong Út o más conocido como Nick Ut. Fue el único fotógrafo que pudo captar la imagen porque tenía una cuarta cámara de reserva: "Cuando pasó la señora mayor con el bebé, todos los fotógrafos tomaron muchísimas fotos y las cámaras hace treinta años no eran como las de ahora. Cuando Kim apareció corriendo, muchos fotógrafos estaban rebobinando el rollo" (BBC, 2006).

Los avances tecnológicos también han facilitado la transmisión de su trabajo, Internet ha hecho que esta sea prácticamente inmediata. Pero también les proporciona una plataforma de lanzamiento, en el que pueden colgar el material descartado, a través de blogs o las redes sociales y llegar a al usuario de una forma directa. Manu Brabo, fotógrafo español galardonado con el Premio Pulitzer en 2013, lo tiene claro: 
La gente debería ver Internet como un diamante en bruto que tenemos que pulir para conseguir que los medios de comunicación y esa herramienta terminen de encontrar la forma de converger. El papel, quieras que no, caerá poco a poco. A las generaciones que estamos más en contacto con Internet nos toca empezar a buscar la fórmula ideal (Brabo, 2013).

Además las nuevas aplicaciones permiten dotar de interactividad a las fotografías permitiendo al público con un clic identificar a las personas que aparecen en la fotografía o abre una pestaña en la que a modo de pie de foto, aporta una información complementaria. Herramientas como Thinglink11, añaden audio, vídeo y enlaces a las fotografías que subimos a la aplicación (Doménech Fabregat \& López Rabadán, 2013). Las limitaciones en papel, son evidentes, una noticia solo puede tener cinco elementos (un texto, un titular, una fotografía, un gráfico y destacados) mientras que en Internet puede llegar hasta 30 (perfiles, transcripciones completas de entrevistas, enlaces a documentos, galerías de fotos, archivo de audio, vídeo, etc.) (Rosenstiel, 2006).

Gracias a estas nuevas posibilidades, según Irala (2011), algunos periodistas gráficos ya piensan en las posibilidades de sus reportajes en la red con anterioridad a realizar el trabajo ya sea porque sean imágenes poco tradicionales, bien por temática bien por su estética más osada que solo tendrán espacio en los medios digitales. Y afirma que la causa es "la pérdida de interés en la imagen de calidad en la prensa en general”. Otros cómo López et al. consideran que "el hipertexto y los contenidos multimedia son la base de nuevas modalidades narrativas en el periodismo" y puede que la fotografía con el móvil sea una modalidad incipiente” (2013, p. 473).

\subsection{Fotoperiodismo con el móvil}

El teléfono móvil con cámara apareció por primera vez en 2001, pero alcanzó popularidad con unos 510 millones vendidos el 2004 (Lister, 2011). Algo que ha afectado a las ventas de las cámaras fotográficas, cayendo un 20\% en 2012 y con una previsión del 44\% para el 2013. Ya los primeros nueve meses del 2013 descendió el porcentaje a un 38,7\%, siendo un 43,9\% entre las cámaras compactas y un $16,7 \%$ en las cámaras réflex. Los fabricantes de teléfonos 
inteligentes saben que la función fotográfica es el segundo uso que hace su propietario, por lo que están mejorando no solo los sensores y las lentes, sino también con el número de aplicaciones y accesorios. Modelos como el Lumia 1020 de Nokia promete fotos de 41 megas, mientras que el Apple iPhone ${ }_{5} \mathrm{~S}$ ha aumentado la cámara a 8 megas, pero además se ha mejorado los estabilizadores de imagen, los flashes, permiten los disparos en ráfaga o la grabación a cámara lenta (Martín J., 2013).

Las cámaras fotográficas han intentado recuperar este terreno incorporando nuevas funciones, que les asemejan a los móviles, como la conectividad Wifi. Ya en 2005, Kodak sacó el modelo Easyshare-One, pero no tuvo continuidad en su catálogo por lo que hubo que esperar al 2009, a que otros fabricantes como Sony y Samsung, lanzaran su modelo que permitía enviar las fotos por Internet. En la actualidad las cámaras han evolucionado mejorando la conectividad permitiendo no sólo el acceso a la red sino también al teléfono móvil pudieron compartir así las fotos en las redes sociales (Peco, 2013). Es paradójico que las cámaras fotográficas evolucionen para parecerse más a los móviles. Y es que estos, han mejorado la calidad de sus fotografías, permiten compartir o mandar estas en tan sólo un clic, algo que los fotógrafos profesionales también han sabido aprovechar.

En 2011 se formó el Grupo de Fotografía con el móvil o "Mobile Photo Group” (MPG), un colectivo internacional creado por fotógrafos de distintas disciplinas con el fin de establecer un estándar para la fotografía móvil de calidad, a través de la exclusividad. Buscaba dar profesionalidad a una actividad que consideraba que ni era amateur ni estaba relacionada con el periodismo ciudadano. Muchos fotógrafos se sintieron amenazados ante esa nueva propuesta, pero también sirvió de inspiración para otros. El grupo se disolvió dos años después por desacuerdos entre los miembros. Pero Oliver Lang, cofundador del grupo, denuncia que se sigue cuestionando la fotografía realizada con un móvil, cuando hay miles de fotógrafos de calidad que trabajan con ella, aunque asume que la idea de la exclusividad ya ha desaparecido (Lang, 2013).

Un ejemplo de este fotoperiodismo con móvil, es el fotógrafo del The New York Times Damon Winter. Ganó el tercer premio del Pictures of theYear en 
2010 por una serie fotográfica tomada con la aplicación Hipstamatic de su iPhone 4. Winter convivió con el Primer Batallón de la Décima División de Montaña en Nahr-i-Sufi (Afganistán) y consideró que era el medio que mejor se adaptaba a lo que quería contar y cómo. Tras llevar seis días con las tropas, se dio cuenta que la cámara del móvil le permitía integrarse mejor entre los soldados y así obtener una mayor espontaneidad en ellos, logrando instantáneas de gran naturalidad, momentos que desaparecían en cuanto sacaba la cámara fotográfica con su gran objetivo. Winter (2011) afirmó que "The beauty of a new tool is that it allows you to see and approach your subjects differently. Using this phone brought me into little details that I would have missed otherwise"1.

Pero no sólo estás imágenes le hicieron merecedor de un tercer premio sino que además estas imágenes fueron portada del periódico The New York Times, lo que suscitó una gran polémica, ya que muchos fotógrafos era muy críticos ante esta nueva forma de trabajo.

Ante las críticas, el fotoperiodista Nick Moir, recuerda que este debate entre profesionales ya se produjo con la cámara digital, muchos profesionales que la rechazaban bendicen en cambio al teléfono móvil porque garantiza máxima calidad y asegura con su conexión a Internet la comunicación (Llanos Martínez, 2013).

Pero el The New York Times también publicó las imágenes realizadas con el móvil, del fotoperiodista de la agencia Getty, Benjamin Lowy, en Kabul (Afganistán) en 2011. La directora de fotografía del periódico, Kathy Ryan, tuvo que salir a defender la decisión del periódico, asegurando que sus fotografías eran más dinámicas, ricas en colores y contrastes añadiendo claridad y textura e incluso poesía a las escenas (Ryan, 11).

Lowy también ganó numerosos premios por su proyecto fotográfico, Iraq. Perspectives realizado también con el iPhone. Lowy entiende este tipo de fotografía como una nueva forma de comunicación o de arte, que según él, no altera la realidad y ayuda a llamar la atención sobre el público (Lowy, 2012). Además considera que las ventajas son evidentes: "es una herramienta

\footnotetext{
${ }^{1}$ La belleza de la nueva herramienta es que te permite ver y acercarte a los sujetos de forma diferente. Utilizando este teléfono me permitió ver detalles que habrá perdido de otra manera.
} 
'anónima', no es pesada e íntima y cómo es rápida, puedo sacar el móvil de mi bolsillo y tomar una foto de lo que está pasando delante de mí” (Lowy, 2013). Él es uno de los fotógrafos más representativos de este tipo de fotografía con innumerables trabajos. Y marcó un hito al ser una fotografía captada con su móvil, la portada de la revista Time para el especial del Huracán Sandy aunque su resolución no cumpliera con los estándares habituales de la publicación (Llanos Martínez, 2013).

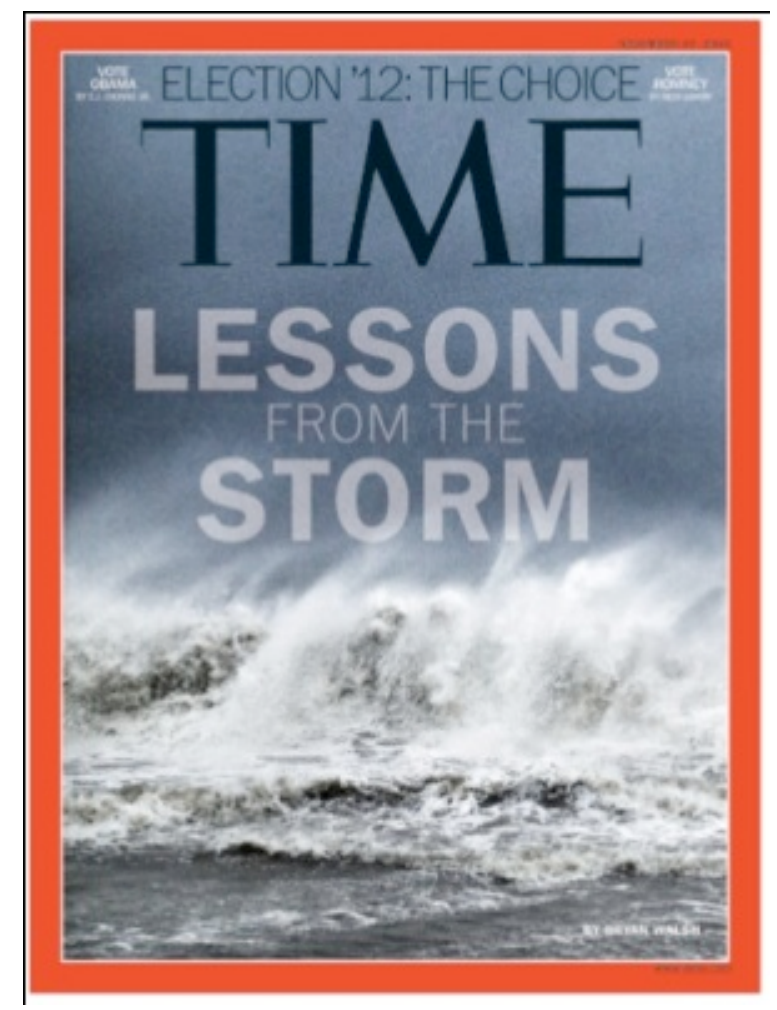

F1: Portada de la revista Time con fotografía realizada por el móvil de Lowy

La revista había encargado a Lowy hacer la cobertura en directo de la llegada del huracán. El fotógrafo colgaba en directo sus fotografías captada con el móvil, en la cuenta de Instagram de la revista:

I also posted live updates. I think for very fluid events, both large scale and fast changing, there will always be a need for live coverage. And the technology is there. The problem arises if the 24 media news cycle will be more interested in quality or quantity of content. In the end, which has happened several times last year - media organizations can just pull non- 
professional's images off social media platforms and publish them for a middling fee ${ }^{2}$. (Lowy, 2013).

Otros profesionales como el estadounidense Peter Di Campo, que ha publicado en The New York Times o National Geographic también ha optado por sustituir la cámara profesional por el teléfono móvil para realizar su proyecto Everyday Africa. Empezó a fotografiar con su móvil escenas cotidianas de la clase media cuando realizaba varios reportajes por África y casi por accidente descubrió que estas instantáneas daban una visión más completa a la realidad africana, más que los proyectos que había planificado. Estas imágenes huían del estereotipo de violencia y conflicto a las que estamos acostumbrados, además de tener una composición menos cuidad permitiéndole una mayor libertad y por tanto, naturalidad a las fotografías (Estrin, 2012).

Theodore Kaye, fotógrafo de Tayikistán y miembro del MPG, recurrió por vez primera a la cámara de su móvil cuando viajó a la provincia china de Xinjiang para atestiguar las tensiones entre una mayoría de población de etnia han y una minoría musulmana, los uigures. Sus rasgos mezcla de asiático y americano despertaba las continuas sospechas de la policía china, por lo que prescindir de su cámara habitual le permitió pasar desapercibido (Llanos Martínez, 2013).

Theodore Kaye apoya este nuevo lenguaje: "nadie ve el mundo en blanco y negro o con los tonos desaturados de las imágenes de un periódico o de una revista, pero todo el mundo las entienden como reales” (Llanos Martínez, 2013). Di Campo ante la polémica sobre los filtro de Instagram comenta que puede que sean demasiado coloristas o que la composición de la imagen sea despreocupada pero entiende que es una nueva técnica.

Y es que cada vez, son más fotógrafos, los que utilizan este dispositivo para realizar su trabajo, como Daniel Berehulak, fotógrafo de Getty, que ha usado

\footnotetext{
${ }^{2}$ También he publicado en directo. Creo que para eventos, tanto a gran escala y de rápida evolución, siempre habrá la necesidad de informar en directo. Y la tecnología está ahí. El problema surge si el medio de comunicación está más interesado en la calidad o en la cantidad de los contenidos. Al final, lo que ha sucedido varias veces el año pasado - es que los medios de comunicación han publicado imágenes de fotógrafos no profesionales colgadas en redes sociales.
} 
la aplicación 645 Pro para un extenso reportaje sobre Afganistán (elpais.es, 2012).

La revista Time ha premiado al jefe de fotografía en Asia de la agencia Associated Press, David Guttenfelder, como el fotógrafo de Instagram del año. El veterano fotoperiodista, siete veces ganador del World Press Photo se alzó con el premio gracias a sus fotografías en Corea del Norte, él es uno de los pocos fotógrafos extranjeros al que se le ha permitido fotografiar en la capital, Pyongyang. Guttenfelder pertenece al grupo de fotógrafos que abrazan Instagram como una oportunidad para compartir las imágenes de una manera única (Tharoor, 2013).

Los premios de fotografía móvil (Mobile Photography Awards) se fundaron en 2011, y tras dos ediciones, se ha convertido en la competición anual más grande en fotografía realizada con la cámara de un móvil o una tableta. El concurso cuenta con 20 categorías que además de dar visibilidad al trabajo de los fotógrafos premiados mediante exhibiciones, ventas en galerías, etc. también dota de una cantidad monetaria, el primer premio con 3.0oo dólares y el segundo, 500 dólares (Berman, 2014).

Michael Christopher Brown retrató la revolución en Libia sólo con un iPhone lo que hizo que le llovieran muchas críticas por el excesivo procesamiento de sus imágenes en Hipstamatic. Pero tomó fotografías que marcaron un punto culmen sobre cómo está cambiando el mundo (Dhaimish, 2012).Brown defiende el empleo de esta herramienta: "Using a mobile phone allows me to be somewhat invisible as a professional photographer; people see me as just another person in the crowd"3. Algo que le ayudó a realizar su trabajo discretamente en el Congo, en concreto en un campamento para desplazados en Kibati. Según él le ayuda a ser mejor fotógrafo porque en vez de concentrarse en la configuración de la cámara y llevar mucho equipo, le permite centrarse más en la situación que en él, "It becomes more about how I feel and what I see"4 (Brown, 2012).

\footnotetext{
3 “El uso de un teléfono móvil me permite ser un tanto invisible como fotógrafo profesional, la gente me ve como una persona más en la multitud".

4 "Se convierte en más cómo me siento y qué estoy viendo"
} 
Son numerosos los fotógrafos que se han apuntado a este tipo de fotografía y prueba de ello es el festival de Los Ángeles, el LA Mobile Arts festival que atrajo a 200 artistas del móvil en su última edición. Pero también desde 2007, existe los iPhone Photography Awards, siendo la competición más antigua, que a pesar no dar premios económicos, cuentan con un gran prestigio.

\subsection{El fotoperiodista ciudadano}

La tecnología desde la última década del siglo XIX, puso en las manos de la gente los medios para fotografiar su vida cotidiana. Algo que no fue posible para el cine o la televisión hasta los años 80, con la aparición de las cámaras de vídeo domésticas. Los avances en los últimos 15 años aventuran que "ahora todos podemos ser productores y distribuidores de medios de comunicación de todo tipo" afirma Lister que además considera que la fotografía podría verse "como un medio que ha estado en la vanguardia de tales avances durante más de un siglo” (2011, p. 30).

La aparición de redes sociales fotográficas o Twitter, se han consolidado en poco tiempo como un nuevo escenario de comunicación, permitiendo a los usuarios compartir sus imágenes con millones de personas en segundos. Según Túñez López (2012), lo que comenzó siendo un punto de reunión entre conocidos también es ahora un escenario de negocio que empieza a ser estudiado e incorporado por los medios de comunicación.

El periodismo ciudadano o participativo como lo definen Bowman y Willis es "el acto de un ciudadano o grupo de ciudadanos que juegan un papel activo en el proceso de colectar, reportar, analizar y diseminar información" (2003, p. 9). Pero no todos los investigadores, como Real et al (2007) o Sorrentino (2013) aceptan llamar a este tipo de comunicación, periodismo y por tanto, prefieren denominarlos comunicadores sociales.

Cuando pasa algo, siempre hay alguien con un móvil con cámara que puede capturar el momento, quizás no compone la imagen cómo lo haría un fotógrafo profesional, pero es el que está en el momento y el sitio dónde se 
produce una noticia. Ante eso los fotógrafos profesionales no pueden competir.

Cada vez son más los usuarios que han sustituido la cámara del móvil por la cámara tradicional, 2 de cada 3, según un estudio realizado por la empresa de telefonía, The Phone House. Además el 87\% de los encuestados afirman que la cámara del móvil, es una de las funcionalidades más utilizadas de los smartphones (Squad, 2013).

A raíz de estos nuevos usos, se crearon aplicaciones específicas para compartir fotografías. El 10 de febrero en 2004, apreció Flickr, que nació como la "primera comunidad online en la que los usuarios podían guardar, organizar, etiquetar y compartir fotos digitalizadas" aunque ya existían otras plataformas como Photobucket, Ofoto, Shutterfly o Snapfish, estas se centraban más en vender las que en compartirlas. A pesar de que actualmente cuente con 92 millones de usuarios en 62 países distintos que suben un millón de fotos al día y participan en dos millones de grupos algunos consideran que su muerte es inminente. Fue superado por Facebook que contaba con 250.000 millones de imágenes en comparación con los 10.000 millones de Flickr y más tarde, por Instagram (Tosas, 2014).

Instagram, originalmente diseñada en 2010 permite además a los usuarios manipular las imágenes con filtros, colores vintage o marcos similares a las placas de las viejas cámaras polaroid. Cuenta con 150 millones de usuarios que comparten 16 billones de fotos según datos de noviembre de 2013 (Caple, 2014). Esta red transformó a los usuarios de los teléfonos inteligentes en fotógrafos amateurs preparados para capturar cualquier instante, pero son muchos los que critican el llamado "efecto Instagram" como detrimento del cuidado y las habilidades que necesita la fotografía, consideran que recortar y añadir filtros para mejorar la imagen es manipular las instantáneas.

La tercera en discordia es Pinterest que se ha convertido en poco tiempo en la tercera red social más popular de Estados Unidos, detrás de Facebook y Twitter, según los datos del estudio The 2012 Digital Marketer: Benchmark and Trend Report. Se trata de una red social basada en un noventa y cinco por ciento en imágenes subidas por los usuarios (el otro cinco es el destinado a los pies de foto) (Ródenas, 2013). 


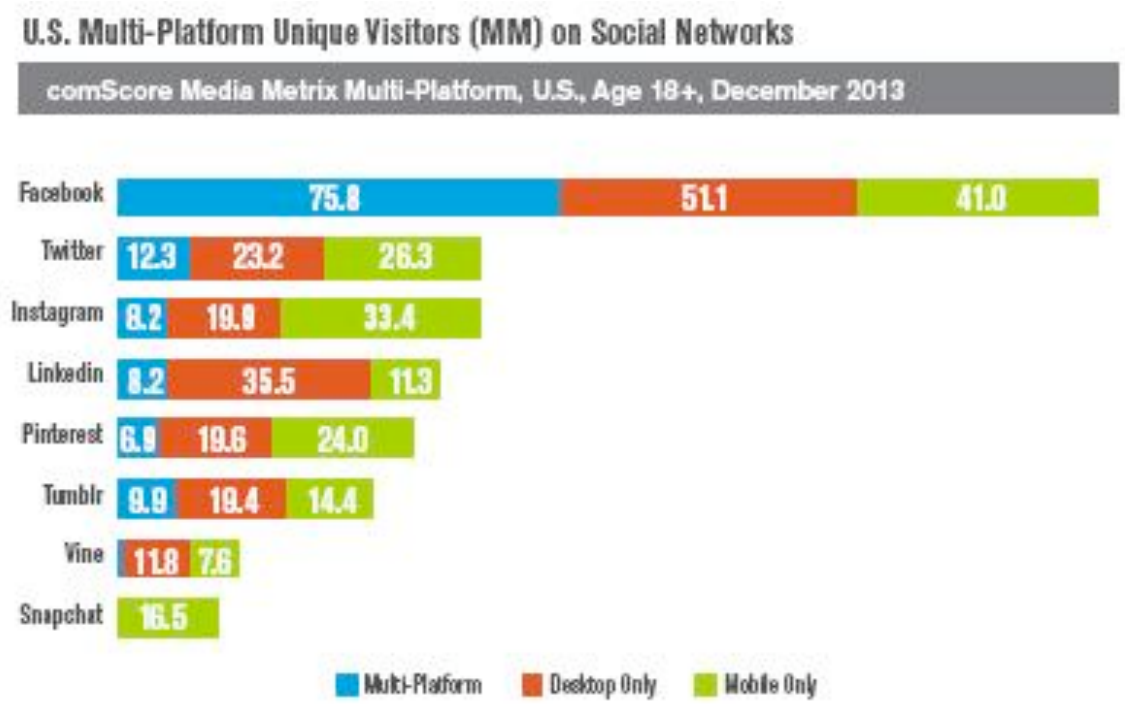

Tabla 1: U.S Digital Future in Focus 2014 de comScore

Pero realmente es Twitter la red que tiene mayor éxito a la hora de difundir las imágenes cuando un acontecimiento se produce, según Llanos Martínez (2013), esta se ha convertido en una fuente informativa y cambiando el lenguaje visual en favor de verdades inéditas, dando lugar a un nuevo fotoperiodismo en la era del teléfono inteligente. Apareciendo nuevos actores como los fotógrafos aficionados, que han sido los que con sus imágenes han ilustrado algunas de las noticias más importantes de los últimos siglos.

El 25 de Julio de 2000, dos turistas españoles fueron los únicos en captar la imagen del Concorde en llamas (F2) pocos segundos antes de estrellarse junto a un hotel del municipio de Gonesse (Paris) (AP, 2008).

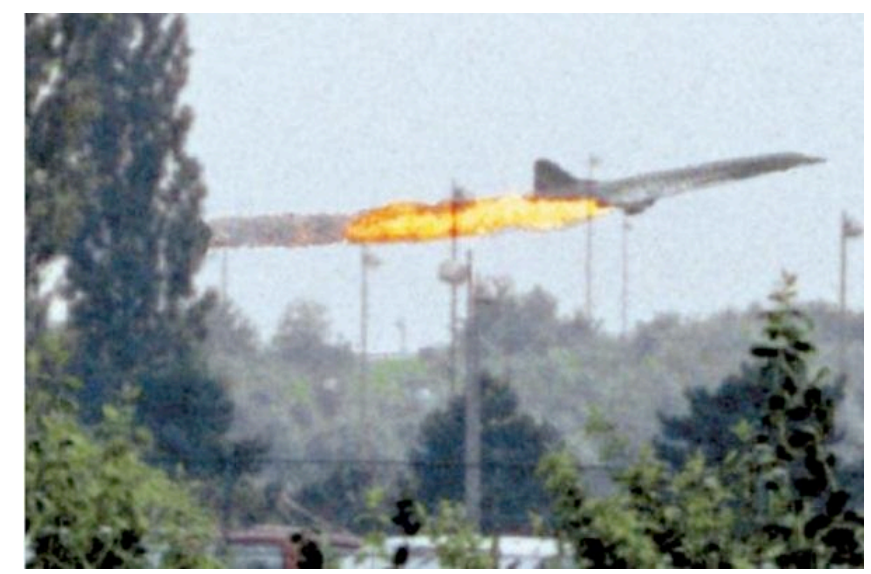

F2: Fotografía del Concorde en llamas realizada por dos turistas 
El 1 de Febrero de 2003, el doctor Scott Lieberman capturaría la imagen icónica de la explosión del Columbia (F3). Su cámara Canon EOS-D6o de 6 mega píxeles captaría la imagen que se publicaría en más de 100 periódicos de todo el mundo y que fue portada de las revistas, Time y Paris Match (Beaujon, 2013). La imagen se pudo transmitir más rápido que nunca gracias a la tecnología.

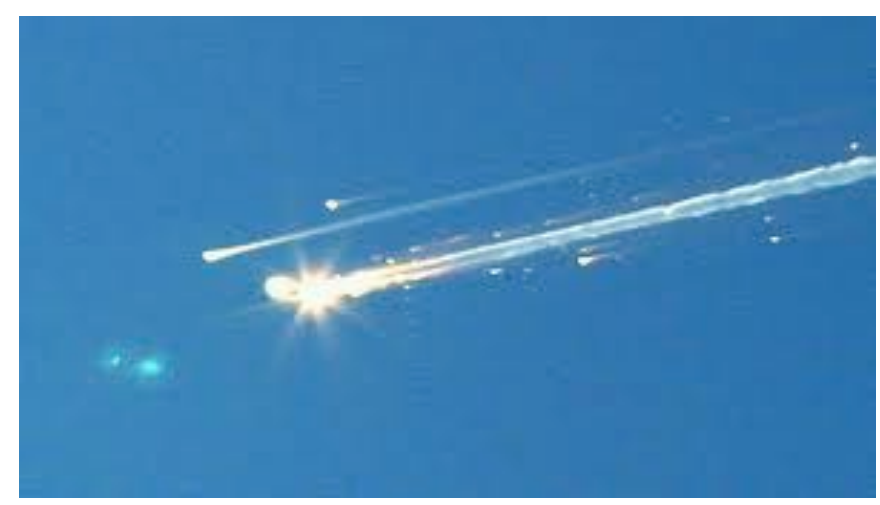

F3: Fotografía de Scott Lieberman

El 5 de Julio de 2005, fue el día que el fenómeno del llamado periodismo ciudadano se consolidó en Gran Bretaña tras los atentados de Londres. La imagen realizada por Alexander Chadwick (F4) de la gente saliendo del túnel del metro, tras una de las explosiones, fue vista por la agencia Associated Press (AP) en la página de noticias de la BBC y decidieron contactar con él para obtener los derechos de la fotografía. Después la agencia distribuiría la fotografía que se convertiría en la imagen de portada de la mayoría de los periódicos y portales de Internet en todo mundo. "Esto fue periodismo ciudadano en acción” afirman desde AP (Lyon \& Ferrara, 2005).

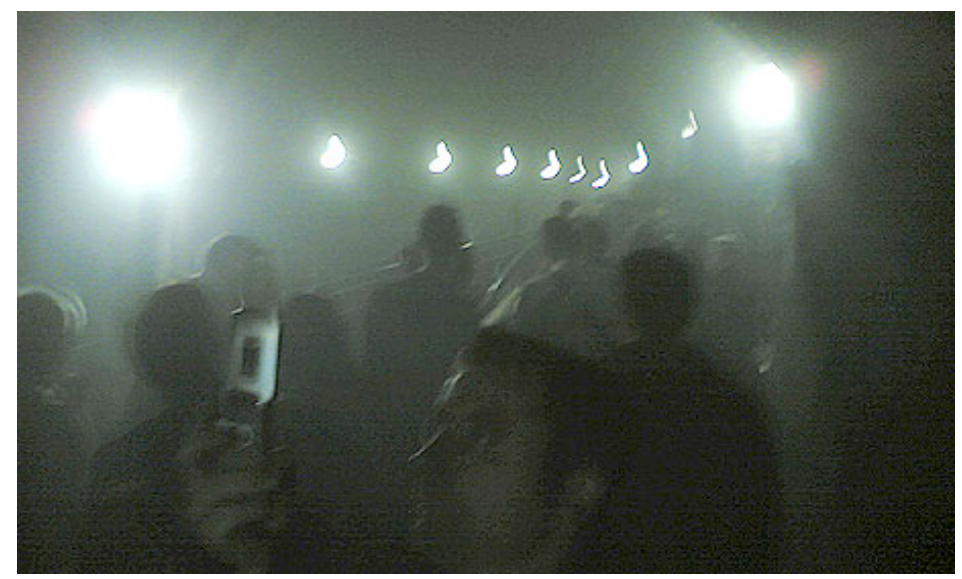

F4: Fotografía de Alexander Chadwick/AP 
El 15 de Enero de 2009, Janis Krums compartió en su cuenta de Twitter (F5), la fotografía del rescate de los pasajeros que iban en el avión de US Airways, que se vio obligado a amenizar en el Hudson por un fallo en los motores. Fue la primera fotografía sobre el suceso y la que recorrería el mundo. Unas 7.0oo personas intentaron verla al mismo tiempo, lo que hizo que Twitpic (el sistema que almacena las fotografías de Twitter) se colgara debido al volumen de visitas. Además Janis se convirtió en protagonista y cadenas como MSNBC le entrevistó tan sólo cuarenta minutos después del accidente como uno de los testigos (Calderón, 2010).

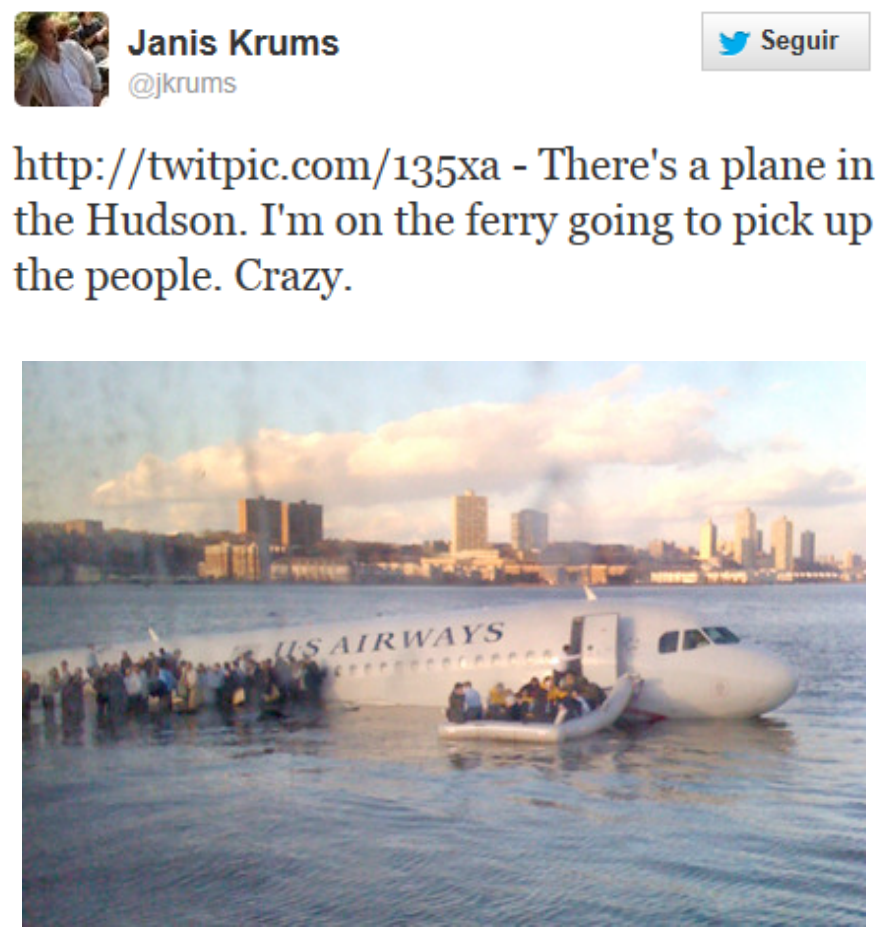

F5: Tuit y fotografía de JanisKrums

La publicación de estas fotografías ciudadanas marca un giro decisivo en la historia del fotoperiodismo gráfico. Según Menajovsky (2014), estas imágenes han probado que informar sobre un gran acontecimiento ya no es terreno exclusivo de profesionales y que lo novedoso radica en que esas imágenes aparecen en la prensa cada vez más frecuente.

La proliferación de móviles con cámaras y el acceso a Internet ha hecho que cada vez que sucede un acontecimiento, los medios acudan a las redes sociales para buscar fotografías y vídeos que luego utilizan sin pagar 
generalmente al autor de las mismas. Pero una sentencia de noviembre de 2013 puede cambiar esta práctica habitual. Un jurado estadounidense condenó a las agencias, France Press (AFP) y Getty Images a pagar un total de un 1,2 millones de dólares al fotógrafo freelance Daniel Morel, en concepto de compensación por daños y perjuicios, después de distribuir sin su permiso las fotografías del terremoto de Haití que había publicado en su cuenta de Twitter (@PhotoMorel) en Enero de 2010. El abogado de AFP argumentó que el hecho que las fotografías se compartieron en Twitter, ello permitía su uso, pero la jueza dictaminó que la red social permite publicar y realizar retuits de las imágenes, pero no concedía el derecho a utilizarlas comercialmente. Las fotografías de Morel fueron publicadas en las portadas de los principales periódicos y también fueron utilizadas profusamente por televisiones y portales de Internet. La calidad de estas imágenes también le harían a Morel ganar dos meses después dos premios World Press Photo (Greenslade, 2013).

A partir de ahora, los medios ya saben que las imágenes en las redes sociales no son gratuitas y no pueden utilizarlas sin el permiso del autor, por eso muchos medios han creado herramientas para que los usuarios se las manden directamente cediendo así los derechos y pudiéndolas utilizar sin pagar por los derechos.

\subsection{Consecuencias en la prensa}

Pero a pesar de abrirse nuevos campos para la fotografía, también los últimos años se produjeron consecuencias negativas para la prensa. Según la American Society of News Editors el sector más afectado por los recortes en el sector han sido los fotógrafos y los cámaras, el $43 \%$ de ellos, ha sido despedidos. Como vemos en la Tabla 2, el número de despedidos pasó de de 6.171 en 2000 a 3.493 en 2012 (Anderson, 2013).

De 2010 a 2012, el porcentaje fue de un 18\%, que llama la atención comprado con otros puestos, como el de los diseñadores, productores online y editores, 0.2\% y un 6\% que afectó a los reporteros y redactores (Anderson, 2013). 


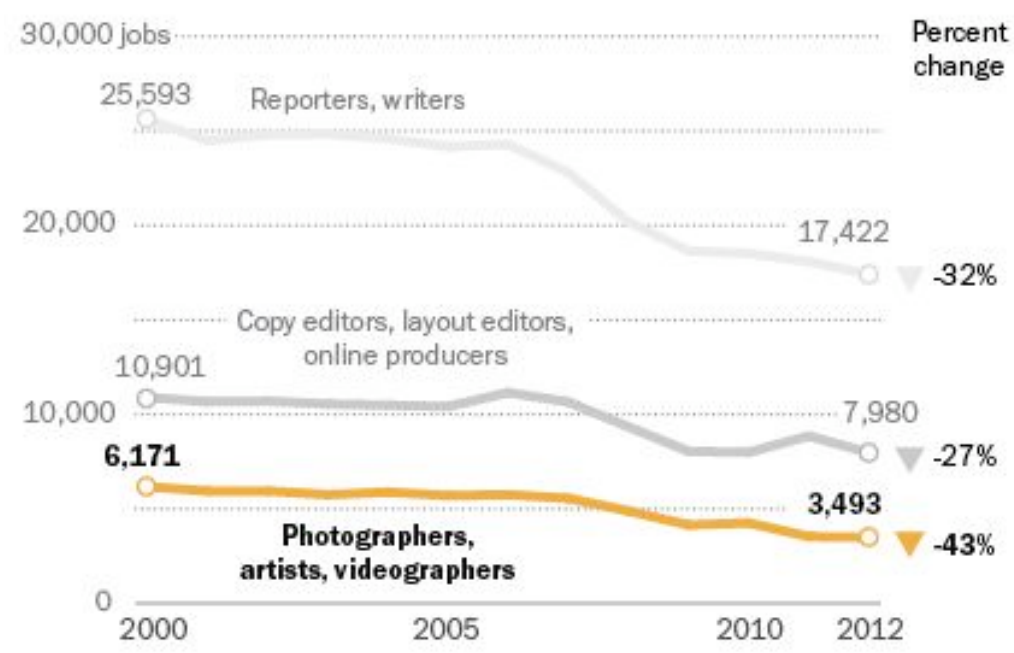

Tabla 2: Fuente Sociedad Americana de Editores de Noticias

En diciembre de 2011, la cadena CNN despidió a 50 empleados, entre ellos fotoperiodistas en parte por el material gratuito que recibe de iReport, su herramienta de periodismo ciudadano. Los precios populares de las cámaras fotográficas con calidad profesional y la posibilidad de compartir al momento las imágenes en redes sociales como Twitter, ha hecho, que cadenas como la americana consideren que no es necesario contar con profesiones para cubrir las noticias. Pero la cadena niega que este haya sido el motivo (Schiller, 2011).

En mayo de 2013, el periódico Chicago Sun-Times, el octavo periódico estadounidense por circulación, despidió a toda su plantilla del departamento de fotografía, 28 empleados entre los que se encontraba John H. White, ganador del Premio Pulitzer en 1982. En un principio se pensaba que fotógrafos freelance suministrarían las imágenes, pero días después del despido, se anunció que todos los reporteros recibirían un curso básico de fotografía con el iPhone. El periódico explica que su objetivo es de dar mayor inmediatez en la publicación en su versión web y la inclusión de un mayor número de vídeos (Europa Press, 2013).

En Octubre del mismo, año, el Atlanta Journal Constitution anunció el despido de diez de sus fotógrafos y un mes después anunció que los restantes se convertirían en periodistas multimedia que suministrarían vídeos no sólo a la web del periódico sino también a las redes sociales, aplicaciones, etc. Para ello les dotarían de iPhones (Hare, 2013). En ese mismo mes, el Times 
Herald-Record de Nueva York también prescindió de sus cuatro fotógrafos de plantilla (Anderson, 2013).

Pero lo más preocupante es lo que hay detrás de los recortes, "nuevas tecnologías", "realidad económica”, "redes sociales" y sobretodo "ciudadanos y no profesionales” son algunos de los que aportan imágenes cuando sucede algo (Caple, 2014).

El diario francés Libération, el 14 de noviembre de 2013, publicó por primera vez en su historia una edición sin ninguna fotografía (F6). En la portada lo anunciaba: "pese a las apariencias, el número especial que tiene entre las manos no es en absoluto un buen periódico sin imágenes”. Su objetivo era reivindicar la importancia de las imágenes como elemento esencial de información y homenajearla. Las páginas interiores mantuvieron los huecos que ocupan normalmente las imágenes, incluyendo también los pies de foto. Esto buscaba llamar la atención del espectador y constatar cómo su ausencia demostraba lo esenciales que son para la comprensión de las noticias. Todas las fotografías previstas se publicaron en una doble página al final de la edición (El Mundo, 2013).

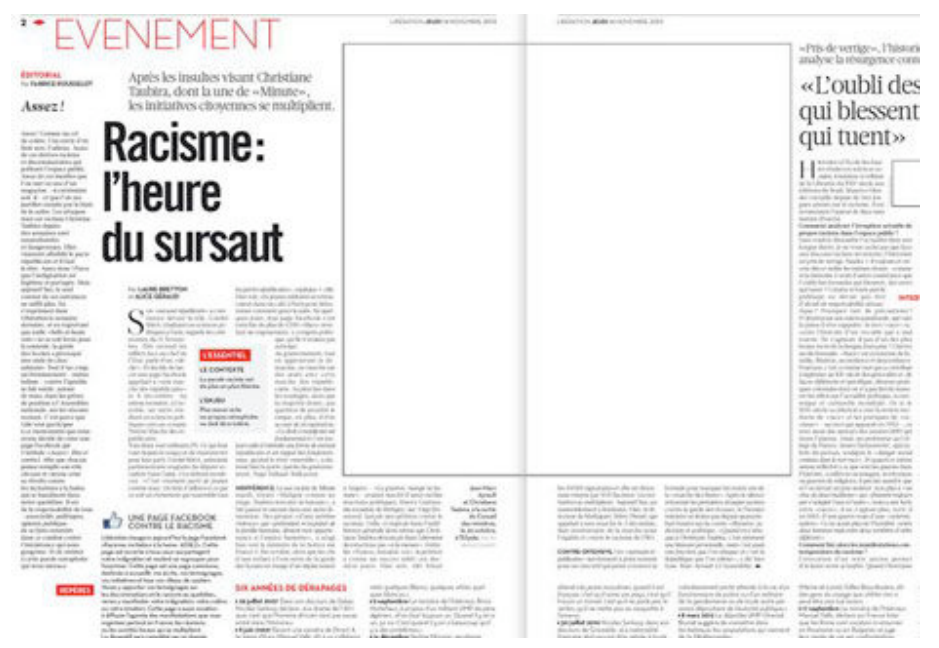

F6: Páginas del diario Libération sin fotografías

\section{Conclusiones}

Pareciera que en la actualidad el fotoperiodismo está en crisis por la popularización de los teléfonos móviles con cámara y su conexión a Internet, lo que ha hecho que existan miles de millones de potenciales 
"fotoperiodistas" por todo el mundo. Es difícil, en los últimos años, que no exista una instantánea de un suceso cuando se produce. Esto no tendría tanta importancia dentro del periodismo, si los medios de comunicación no las utilizaran para ilustrar sus informaciones. Pero esta nueva comunicación, las redes sociales, en concreto Twitter, ha provocado un cambio en el paradigma no solo comunicativo sino también informativo, que es difícil de determinar si terminará quedándose como la fórmula de trabajo fotográfico en los medios de comunicación.

Los medios han rebajado sus estándares de calidad visual para dar cabida a todas estas imágenes, que además tienen la virtud de ser gratuitas. La crisis en el periodismo unido a esta facilidad de conseguir material sin coste, ha hecho que muchos medios opten por despedir a sus fotógrafos entendiendo que son prescindibles.

El trabajo del llamado periodista ciudadano no se puede comparar al del fotoperiodista profesional, cualquiera puede hacer una fotografía de un suceso, encontrarse con una buena instantánea, pero se perderán cientos de ellas, por ello, más que nunca es necesaria la figura de los fotoperiodistas quienes de alguna manera han catalogado sucesos importantes y han convertido en iconos a esas instantáneas que reflejan eso, un suceso de alto impacto social.

Este profesional gráfico está obligado a adaptarse a los nuevos medios, como fotografiar a través del móvil o con cámaras que directamente envían las instantáneas al medio o a la red social del mismo, para ganar en inmediatez, pero si los medios se dan cuenta de su valía, contaremos con fotografías de calidad periodística de nuevo en las páginas de los periódicos o portales de Internet.

Con la aparición de la televisión, el fotoperiodismo fue capaz de salir reforzado, dejando en la retina cientos de imágenes icónicas como la del os soldados clavando la bandera de Estados Unidos en IwoJima, "la niña del Napalm" o el hombre enfrentándose a los tanques de Tiannanmen, que a pesar de existir imágenes de vídeo, la historia recuerda las instantáneas. 
El fotoperiodismo debe reinventarse de nuevo y encontrar su sitio en este nuevo panorama, recordando que el valor de una buena fotografía, no es lo que capta, sino lo que cuenta y esa capacidad no la tiene cualquiera con una cámara.

\section{Referencias bibliográficas}

Anderson, M. (11 de 11 de 2013). At newspapers, photographers feel the brunt of job cuts. Recuperado el 2 de 3 de 2014, de http://www.pewresearch.org/fact-tank/2013/11/11/at-newspapersphotographers-feel-the-brunt-of-job-cuts/

AP. (12 de 3 de 2008). Dos trabajadores de Continental podrían ser juzgados por el accidente del Concorde. Recuperado el 2 de 4 de 2014, de http://www.lavanguardia.com/sucesos/20080312/53445029316/dostrabajadores-de-continental-podrian-ser-juzgados-por-el-accidente-delconcorde.html

Aragó, F. (1987). Rapport sur le Daguerréotype. En M. Frizot, \& D. Françoise, Du bon usage de la photographie. Paris: Centre National de la Photographie, pp. 11-18.

Baqué, D. (2003). La fotografía plástica. Barcelona: Gustavo Gili.

BBC. (13 de 1 de 2006). "iDios mío, no quiero que muera!" . Recuperado el 17 de 4 de 2013, de http://news.bbc.co.uk/hi/spanish/international/newsid_461000o/4610 456.stm

Beaujon, A. (1 de 2 de 2013). Texas doctor who captured iconic image of Columbia disaster is now a working photographer. Recuperado el 2 de 3 de 2014, de http://www.poynter.org/latestnews/mediawire/202526/texas-doctor-who-captured-iconic-image-ofcolumbia-disaster-is-now-a-working-photographer/

Berman, D. (2014). About the Mobile Photography Awards. Recuperado el 7 de 3 de 2014, de http://mobilephotoawards.com/about/

Brabo, M. (3 de 5 de 2013). Manu Brabo: "Si la gente gritara en la calle lo que grita en Facebook, sería la hostia”. (R. Lobo, Entrevistador)

Braojos Garrido, A., García González, G., De Pablo Contreras, S., Paz Rebollo, M. A., \& Scuzle Schneider, I. (1999). Historia del periodismo universal. Madrid: Síntesis.

Brown, M. C. (16 de 8 de 2012). An iPhone in the DRC: Photos by Michael Christopher Brown. Recuperado el 9 de 3 de 2014, de http://lightbox.time.com/2012/o8/16/an-iphone-in-congo-photos-bymichael-christopher-brown/\#1

Calderón, V. (21 de 3 de 2010). La fama en 140 caracteres. Recuperado el 8 de 4 de 2013, de www.elpais.es: http://elpais.com/diario/2010/o3/21/sociedad/1269126006_850215.ht $\mathrm{ml}$ 
Campany, D. (2007). Seguridad en la parálisis: algunas observaciones sobre los problemas de la "fotografía tardía". En D. Green, ¿Qué ha sido de la fotografía? Barcelona: Gustavo Gili, pp. 135-146.

Campbell, D. (2010). Photojournalism in the New Media Economy. Nieman Report, pp. 15-17. http://niemanreports.org/articles/photojournalismin-the-new-media-economy/

Caple, H. (10 de 1 de 2014). This is the end of the press photographer. $\begin{array}{llllll}\text { Recuperado el } & 28 & \text { de } & 2 & \text { de }\end{array}$ https://reutersinstitute.politics.ox.ac.uk/about/news/item/article/thisis-the-end-for-the-press-photo.html

Chenu, J. (1984). Peirce. Textes anticartésiens. Paris: Aubier.

Corral, P. (2012). La fotografía como lenguaje. Cuadernos de periodistas, pp. 6779.

Danto, A. (2002). La transfiguración del lugar común. Barcelona: Paidós.

Daston, L., \& Galison, P. (2010). Objectivity. New York: Zone Books.

Derrida, J. (1997). Mal de archivo: una impresión freudiana. Madrid: Trotta.

Dhaimish, S. (17 de 11 de 2012). Michael Christopher Brown: revolution through an iPhone. Recuperado el 5 de 3 de 2014, de http://libya.tv/en/michael-christopher-brown-revolution-through-aniphone/

Doménech Fabregat, H., \& López Rabadán, P. (15 de 3 de 2013). XIV CONGRESO DE PERIODISMO DIGITAL. Recuperado el 1 de 04 de 2013, de www.congresoperiodismo.com: http://www.congresoperiodismo.com/pdf/libro2013.pdf

Durand, R. (1995). Le temps de l'image. Madrid: La Différence.

El Mundo. (14 de 11 de 2013). El diario 'Libération' se publica sin imágenes para reivindicar su importancia. Recuperado el 1 de 3 de 2014, de http://www.elmundo.es/television/2013/11/14/5284c12foab74072388b 457f.html

elpais.es. (13 de 12 de 2012). Afganistán fotografiado con un iPhone. Recuperado el 15 de 4 de 2013, de www.elpais.es: http://elpais.com/elpais/2012/12/13/album/1355410779_241053.html\# 1355410779_241053_1355411033

Enwezor, O. (2008). Archive fever. Uses of documentary in contemporary art. New York: International Center of Photography/ Steidl.

Esparza, R. (2 de junio de 2005). Bernd y Hilla Becher: "Estamos más cerca de la fotografía del XIX que de la posmodernidad”. El Cultural , 38-39.

Estrin, J. (17 de 9 de 2012). Picturing Everyday Life in Africa. Recuperado el 9 de 4 de 2013, de The New York Times: http://lens.blogs.nytimes.com/2012/o9/17/picturing-everyday-life-inafrica/

Europa Press. (3 de 6 de 2013). El Chicago Sun-Times sustituye a su plantilla de fotógrafos por iPhones. Recuperado el 1 de 3 de 2014, de http://www.europapress.es/portaltic/sector/noticia-chicago-sun-timessustituye-plantilla-fotografos-iphones-20130603105513.html 
Foucault, M. (2002). La arqueología del saber. Buenos Aires: Siglo XXI.

Freund, G. (2011). La fotografía como documento social. Barcelona: Gustavo Gili.

Galassi, P. (2007). Jeff Wall. New York: The Museum of Modern Art.

Greene, d. L. (Spring de 1993). Dennis Oppenheim: No Photography. Spot . (H. C. Photography, Ed.) Houston, EEUU. Recuperado el 21 de 10 de 2014, de Spot:

http://spot.hcponline.org/pages/dennis_oppenheim_no_photography_1 915.asp

Greenslade, R. (26 de 11 de 2013). Agencies ordered to pay $\$ 1.2 \mathrm{~m}$ for photographs taken from Twitter. Recuperado el 8 de 3 de 2014, de http://www.theguardian.com/media/greenslade/2013/nov/26/newsagencies-news-photography

Guerra, C. (2014). El despliegue del dispositivo documental. En X. Ribas, Nitrato. Barcelona: MACBA, p. 15.

Hare, K. (5 de 11 de 2013). Atlanta Journal-Constitution photographers will become 'multimedia visual journalists'. Recuperado el 2 de 3 de 2014, de http://www.poynter.org/latest-news/mediawire/228511/atlanta-journalconstitution-photographers-will-become-multimedia-visual-journalists/

Hicks, W. (1973). Words and Pictures. New York: Arno Press.

Hill, P., \& Cooper, T. (1980). Diálogos con la fotografía. Barcelona: Gustavo Gili.

Holmes, O. W. (1981). The Stereoscope and the Stereograph. En V. Goldberg, Photography in print. New York: Touchstone, pp. 100-114.

Irala, P. (2011). Fotoperiodismo con teléfono móvil. En J. J. Verón, \& F. (. Sabés, La investigación en periodismo digital. Algunos trabajos desde el ámbito universitario. Zaragoza: Asociación de Periodistas de Aragón, pp. 385-397.

Irala, P. (2011). Retórica fotográfica y periodismo literario. Estudios sobre el Mensaje Periodístico, pp. 57-65.

Kashi, E. (2010). Journey to a New Beginning. Nieman Report, pp. 8-10.

Katz, L. (1981). An interview with Walker Evans. En V. Goldberg, Photography in print. New York: Touchstone, pp. 358-369.

Kuper, S. (31 de 5 de 2013). Interview: John Morris on his friend Robert Capa. Recuperado el 31 de 5 de 2013, de www.ft.com: http://www.ft.com/cms/s/2/3d37ao3e-c8be-11e2-acc6oo144feab7de.html\#slideo

Lang, O. (26 de 2 de 2013). The Mobile Photo Group - an Obituary. Recuperado el 1 de 3 de 2014, de http://oggsie.com/blog/13747638/mpg-is-dead

Lippard, L. (2004). Seis años: la desmaterialización del objeto artístico de 1966 a 1972. Madrid: Akal.

Lister, M. (2011). ¿Demasiadas fotografías? La fotografía como contenido generado por el usuario. adComunica. Revista Científica de Estrategias, Tendencias e Innovación en Comunicación, pp. 25-41. 
Llanos Martínez, H. (6 de 1 de 2013). El fotoperiodismo de 'smartphone'. Recuperado el 01 de 04 de 2013, de www.elpais.es: http://cultura.elpais.com/cultura/2013/o1/o6/actualidad/1357481716_4 14577.html

Lowy, B. (2 de 5 de 2012). Ben Lowy: Virtually Unfiltered. (J. Estrin, Entrevistador)

Lowy, B. (5 de 2 de 2013). War through an IPhone Lens. Q\&A with Ben Lowy. (EyeEm, Entrevistador)

Lugon, O. (2010). El estilo documental. Salamanca: Ediciones Universidad de Salamanca.

López, J., \& Olivera, M. (2013). La nueva ecología de la información y la documentación en la sociedad del conocimiento: rutinas de elaboración y gestión de contenidos de los diarios digitales españoles. Estudios sobre el Mensaje Periodístico, pp. 471-486.

Lyon, S., \& Ferrara, L. (2005). With Citizens' Visual News Coverage Standards Don't Change. Nieman Reports, pp. 16-17.

Maciá Barber, C. (2007). No todos somos ya periodistas. Un análisis de la utopía del periodismo ciudadano desde la perspectiva del reportaje interpretativo. Estudios sobre el Mensaje Periodístico, pp. 123-144.

Marinello, J. D. (1996). La apuesta de Gates. Cuadernos de información, pp. 6871.

Martí, E. (2001). Arrogancia Cero. En M. Leguineche, \& G. Sánchez, Los ojos de la guerra. Madrid: Random House Mondadori.

Martín, J. (12 de 11 de 2013). El 'smartphone' también se come a la cámara réflex. Recuperado el 6 de 3 de 2014, de http://tecnologia.elpais.com/tecnologia/2013/11/12/actualidad/1384272 506_680275.html

Martín, X. (2013). Cuatro despidos más en el grupo de 'Diario de Alcalá'. Retrieved 12 12, 2014 from http://www.apmadrid.es/noticiasdestacados/1-columna-abajo/cuatro-despidos-mas-en-el-grupo-dediario-de-alcala

Menajovsky, J. (2014). El fotoperiodismo en crisis: crónica de una agonía anunciada. Recuperado el 3 de 3 de 2014, de http://www.palermo.edu/cienciassociales/opinion/menajovsky.html

Miles, M. (2010). The Drive to Archive: Conceptual Documentary Photobook Design. Photographies, 3 (1), pp. 49-68.

Peco, R. (29 de 12 de 2013). Guía práctica para elegir la mejor cámara de fotos con conexión wifi. Recuperado el 8 de 3 de 2014, de http://www.elconfidencial.com/tecnologia/2013-12-29/guia-practicapara-elegir-la-mejor-camara-de-fotos-con-conexion-wifi_70815/

Peirce, C. S. (1987). Obra lógico semiótica. Madrid: Taurus.

Pizarroso Quintero, A., González San Ruperto, M., \& Sapag Muñoz de la Peña, P. (2007). Periodismo de guerra. Madrid: Síntesis.

Renger-Patzsch, A. (1989). Joy Before the object. En C. Phillips, Photography in the Modern Era. New York: Aperture. 
Ribas, X. (2009). Rastros. Salamanca: Eds. Universidad de Salamanca.

Rosenstiel, T. (2006). Periodismo coherente y otras estrategias para sobrevivir. Cuadernos de periodistas, pp. 77-82.

Ródenas, G. (2013). Capturar es compartir. Filosofía, redes sociales y fotografía 2.0. Enrahonar. Quaderns de Filosofia, pp. 59-72.

Ryan, K. (20 de 10 de 11). Hipstamatic in Kabul. Recuperado el 9 de 4 de 2013, de The New York Times: http://6thfloor.blogs.nytimes.com/2011/10/20/hipstamatic-in-kabul/

Schaeffer, J.-M. (1990). La imagen precaria. Madrid: Cátedra.

Schiller, J. (20 de 12 de 2011). CNN's iReport Produces Controversy, Llama Photos. Recuperado el 1 de 3 de 2014, de http://www.wired.com/rawfile/2011/12/cnns-ireport-producescontroversy-llama-photos/

Squad, G. (28 de 6 de 2013). El smartphone 'jubila' a la cámara de fotos en vacaciones. Recuperado el 29 de 2 de 2014, de http://blog.phonehouse.es/index.php/2013/o6/28/el-smartphonejubila-a-la-camara-de-fotos-en-vacaciones/

Suárez, R. (2013). El tratamiento informativo de los conflictos bélicos. Recuperado el 3 de 2 de 2013, de www.comunicacionymedios.com: http://www.comunicacionymedios.com/comunicacion/television/textos/ roberto_suarez_tratamiento_conflictos.htm

Szarkowski, J. (1978). Mirrors and Windows. New York: The Museum of Modern Art.

Túnez López, M. (2012). Los periódicos en las redes sociales: audiencias, contenido, interactividad y estrategias comerciales. Estudios sobre el mensaje periodístico, pp. 221-239.

Teige, K. (1989). The tasks of Modern Photography. En C. Phillips, Photography in the Modern Era. New York: The Metropolitan Museum of ArtAperture, pp. 312-322.

Tharoor, I. (18 de 12 de 2013). David Guttenfelder Is TIME's Pick for Instagram Photographer of the Year. Recuperado el 8 de 3 de 2014, de http://time.com/11618/david-guttenfelder-is-times-pick-for-instagramphotographer-of-the-year/

Tosas, G. (12 de 2 de 2014). Flickr cumple 10 años de altibajos. Recuperado el 12 de 3 de 2014, de http://www.lavanguardia.com/tecnologia/redessociales/20140212/54400194600/flickr-10-anos.html

Winter, D. (13 de 2 de 2011). Through My Eye, Not Hipstamatic's. Recuperado el 9 de 4 de 2013, de The New York Times: http://lens.blogs.nytimes.com/2011/02/11/through-my-eye-nothipstamatics/

Cómo citar: Lavín de las Heras, E. \& RömerPieretti, M. (2015). "Fotoperiodismo con el móvil: ¿el fin o reinvención de los fotógrafos de prensa?”. Fotocinema. Revista científica de cine y fotografía, 11, pp. 189-214. Disponible: http://www.revistafotocinema.com/ 